\title{
Employee Benefits: Analysis of Starbucks, Amazon, and Walmart's Employee Benefits Program
}

\author{
Dr. Arthur M. Baldonado, Ph.D \\ Columbia Southern University, 21982 University Lane, Orange Beach AL 36561, USA
}

\author{
*Corresponding Author: Dr. Arthur M. Baldonado, Columbia Southern University, 21982 University \\ Lane. Orange Beach AL 36561. USA
}

\begin{abstract}
What makes an effective employee benefit program? Employee benefits are vitally important to an organization's recruitment and retention strategy. This article depicts lessons that can be extracted from three corporations espousing great employee benefits program-Starbucks, Amazon, and Walmart. These companies have become well-known for their success with employees and customers alike.
\end{abstract}

Keywords: Employee Benefits, Compensation, Starbucks, Amazon, and Walmart

\section{INTRODUCTION}

What makes an effective employee benefit program? Employee benefits are vitally important to an organization's recruitment and retention strategy. Sinclair et al. (2005) noted that effective compensation practices provide companies with a competitive advantage by increasing their ability to attract and retain employees. This article depicts lessons that can be extracted from three corporations espousing great employee benefits program- Starbucks, Amazon, and Walmart. These companies have become well-known for their success with employees and customers alike.

Starbucks, Amazon, and Walmart are some of the companies this author selected to extract lessons from in this article. These companies have solid employee benefits program and are ranked in Forbes' "Fortune 500" listing of world's largest companies (Forbes, 2020). Managers can learn from these companies' employee benefits program.

The purpose of this article is to accomplish the following: 1) briefly define compensation and employee benefits, 2) describe Starbucks, Amazon, and Walmart employee benefits program, and 3) provide practical application of effective employee benefits program.

\section{COMPENSATION AND EMPLOYEe BenEFITS DEFINED}

It is important to define compensation and employee benefits. Martocchio (2017) noted that compensation represent both intrinsic and extrinsic rewards employees receive for performing their jobs and for their membership as employees. Intrinsic compensation involves worker's psychological mindsets that result from performing their jobs while extrinsic compensation includes monetary and nonmonetary reward. Core compensations represent monetary compensation (i.e., wages or salary) while nonmonetary rewards include discretionary benefits as well as mandated benefits that employees receive as part of an employment arrangement. Mandated benefits are legally required to include social security program, workers compensation, unpaid family and medical leave, and health insurance (Martocchio, 2017).

Employee benefits (or discretionary benefits) are offered at the will or discretion of the company and include variety of programs. These programs fall into three broad categories: paid time off (i.e., vacation), employee services (i.e., wellness programs), and protection programs (i.e., life insurance). Benefits program design entails consideration of many factors including who is eligible to participate, financing of benefits, employee choice, cost containment, and communication plan. While employee benefits are costly to a business, they are a vital component of the total compensation system as they promote behaviors through promoting wellness, financial security, work-life balance, and more (Martocchio, 2017). 
Firms utilize various compensation systems to enhance employee productivity (Kang et al., 2016). Compensation professionals work with organizational leaders to determine the best compensation plans that contribute to recruitment, employee job performance, and retention (Martocchio, 2017). Let us now examine three companies depicting excellent employee benefit programs.

\section{ORGANIZATIONAL BACKGROUND}

Three companies are examined in this section for their employee benefit programs - Starbucks, Amazon, and Walmart.

\section{Starbucks}

Starbucks Corporation is an American company and one of the largest coffeehouse chains in the world. Established in 1971, Starbucks operates in over 70 countries of more than 24,000 retail stores. Headquartered in Seattle, Washington, Starbucks reported an annual revenue of over \$26 billion in 2019. With solid leadership, Starbucks employs over 277,000 workers worldwide. Starbucks consistently received top accolades such as Fortune Magazine 2009-2017 "World's Most Admired Companies", Glassdoor's 2018"Best Places to Work For", and Ethisphere Institute 2007-2017 "World's Most Ethical Companies" (Starbucks, 2020).

Starbucks is renowned for treating its 346,000-plus employees well (referred as "partners"). The coffee chain offers world-class benefits/programs for eligible part-time and full-time workers with Total Rewards package including base pay and bonus, benefits, retirement savings, stock, and perks. Starbuck's website listed the following employee benefit programs:

- Health Coverage, Stock and Savings, Paid-Time Off, Parental Leave, Education, Commuter Benefit, Partner Assistance, and other perks such as coffee/tea markout, in-store discount, recognition programs, partner networks, affiliate discounts, Care@Work by care.com, Spotify premium subscription, elite athlete program, matching gift program, and on-site gym, daycare, and dry cleaning (Starbucks, 2020).

\section{Amazon}

Amazon is a massive online retailer in the world having a global presence to over a dozen countries. Founded by Jeff Bezos in 1994, Amazon is headquartered in Seattle, Washington with a 2019 annual revenue of over $\$ 280$ billion. Amazon has become the largest online ecommerce retailer, and one of the most powerful brands in the world (Ecommerce Platforms, 2020). With amazing customerfocused philosophy, Amazon consistently garnered top awards such as American Customer Satisfaction Index 2020, Forbes' World Best Employers 2020 and Global Company, and BrandZ 2020 Most Valuable Brand (Amazon, 2020).

Since becoming the largest online retailer in the world, Amazon has become the second largest employer in the United States with over 750,000 employees. Amazon offers the following full range of benefits to full-time, part-time, and seasonal workers and eligible family members:

- Medical, prescription drug, dental, and vision coverage, Medical Advice Line, 401k savings plan, Paid time-off and Holiday overtime pay, Network support such as employee assistance program and counseling, Adoption Assistance, Maternity and Paternity leave, Amazon employee discount, and Career Choice Tuition Assistance (Amazon, 2020).

\section{Walmart}

Walmart, headquartered in Bentonville, Arkansas,is an American operator of discount stores and world's largest retailer. Founded by Sam Walton in 1962, Walmart has over 11,500 stores worldwide with 2020 annual revenue of $\$ 524$ billion (Britannica, 2020). Since becoming the largest U.S. corporation, Walmart is known for its emphasis on customer attention, cost controls, and efficiencies in its distribution networks. Walmart consistently receives top honors such as Forbes list 2020 World's Most Valuable Brands, America's Best Employers by State, and Global 2000 Companies (Forbes, 2020).

Walmart employs over 2.2 million associates worldwide. Often referred to as "Associates", the following benefits are available to full-time and part-time employees:

- Health and insurance option, maternity and parental leave, paid time off, retirement planning, associate discounts, adoption expense, and education benefits (Walmart, 2020). 


\section{Analysis of Starbucks, Amazon, AND Walmart Employee Benefits Program}

Employee benefits are vitally important to organizational success. Although these three companies offer unique discretionary benefits, it is interesting to note their similarities relating to employee benefits. All three companies offered:

- Health or medical coverage to employees

- Discounts to their own products or services

- Retirement, PTO, and tuition assistance options

This author observed unique employee perks available to employees. For instance, Starbucks offers workers Spotify subscription, matching gift program to a nonprofit organization, and stock options. Amazon offers a Medical Advice Line 24/7 for free consultation and holiday overtime pay to its employees. Finally, Walmart offers procedures such as spine and heart procedures at no cost to associates.

Starbucks, Amazon, and Walmart are great examples of effective employee benefits programs. Indeed, a well-designed employee benefits package helps rebuild loyalty, drive employee engagement, and encourage workers to stay on the job (Scorza, 2011).For benefits to make a positive impact on an individual, the individual first needs to be aware of and understand the benefits their employer currently offers (Peggy, 2009).

\section{Practical Application}

Effective compensation practices provide organizations with a competitive advantage by increasing their ability to attract and retain employees (Sinclair \& Wright, 2005). Research has shown that employee benefits can boost employee motivation and in turn, the increased motivation positively influences both individual and firm performance (Kang et al., 2016).

Successfully communicating a company's compensation program can prove beneficial to employee engagement, morale, productivity, recruitment, and retention. Peggy (2009) listed series of steps for organizations to ensure benefits communication is working and engaging employees in a positive manner.

1) Review your benefits portfolio

2) Define what you want to say

3) Ask your provider for assistance

4) Seek help from line managers

5) Seek a variety of communication channels

6) Maintain regular communication

7) Step back and review what you are doing (p. 11)

Organizations should encourage employee benefit use to facilitate productivity and foster healthy employee-employer relationships (Sinclair \& Wright, 2005). Effective discretionary benefit program can increase employee loyalty, focus and productivity, attendance, retention, and recruiting.

\section{CONCLuSion}

This article defined employee benefits and compensation and reviewed Starbucks, Amazon, and Walmart employee benefits program. Employees have unique needs, and organizations must constantly look for ways to effectively recruit and retain productive workers. Successful organizations know how to leverage employee perks to their advantage.

\section{REFERENCES}

Amazon. (2020). Retrieved from https://www.amazondelivers.jobs/about/benefits/

Bort, J. (2014). The 25 most enjoyable companies to work for. Retrieved from http://www.businessinsider.com/ 25-best-corporate-cultures-2014-8

Britannica. (2020). Walmart. Retrieved from https://www.britannica.com/topic/Walmart 
Ecommerce Platforms. (2020). What is amazon? Retrieved from https://ecommerce-platforms.com/glossary/ amazon

Forbes. (2020). Global 2000 The world's largest public companies. Retrieved from https://fortune.com/fortune $500 / 2020 / \mathrm{search} /$

Kang, D., Yu, G., \& Lee, S. (2016). Disentangling the effects of the employee benefits on employee productivity. The Journal of Applied Business Research, 32(5), 1447-1458.

Martocchio, J. J. (2017). Strategic compensation: A human resource management approach (9th ed.). Pearson.

Peggy, T. (2009). Creating engagement through employee benefits. Strategic HR Review, 8(2), 5-12.

Sinclair, R., Leo, M., \& Wright, C. (2005). Benefits system effects on employee benefit knowledge, use, and organizational commitment. Journal of Business and Psychology, (20)1, 3-29.

Starbucks. (2020). Retrieved from https://www.starbucks.com/about-us/company-information

Walmart. (2020). Retrieved from https://corporate.walmart.com/our-story

Scorza, J. (2011). Benefits can boost employee loyalty. Retrieved from https://www.shrm.org/resources andtools/hr-topics/benefits/pages/benefits_loyalty.aspx

Workstars. (2020). 20 companies leading the way when it comes to employee perks and benefits. Retrieved from https://www.workstars.com/recognition-and-engagement-blog/2019/11/13/20-companies-leadingthe-way-when-it-comes-to-employee-perks-and-benefits/

Yerkes, L. (2003). How to create a place where people love to work. The Journal for Quality and Participation, 26(4), 47-50.

\section{AUTHOR'S BIOGRAPHY}

Dr. Baldonado, is a faculty member at Columbia Southern University and a military veteran. His areas of expertise include human resources, work motivation and diversity, business administration, and management. Dr. Baldonado has over 20 years of human resources, military, and teaching experience and has published in his field.

Citation: Dr. Baldonado "Employee Benefits: Analysis of Starbucks, Amazon, and Walmart's Employee Benefits Program" International Journal of Managerial Studies and Research (IJMSR), vol 9, no. 1, 2021, pp. 55-58. doi: https://doi.org/10.20431/2349-0349.0901005.

Copyright: ( $) 2021$ Authors. This is an open-access article distributed under the terms of the Creative Commons Attribution License, which permits unrestricted use, distribution, and reproduction in any medium, provided the original author and source are credited. 